\title{
TRAS LA RESTAURACIÓN DEL PUENTE QUE UNE A LA TEORÍA DE LA CIENCIA CON LA TEORÍA GENERAL DEL CONOCIMIENTO: UNA PROPUESTA DE EPISTEMOLOGÍA JURÍDICA QUE VINCULA AL DERECHO CON LA JUSTICIA
}

\author{
Autores: José Alejandro Machado Jiménez y Edgar Antonio Guarín Ramírez* \\ Fecha de recepción: 31 de Enero de 2012 \\ Fecha de evaluación: 21 de febrero de 2012 \\ Fecha de aprobación: 21 de marzo de 2012
}

\section{RESUMEN}

Este artículo presenta una alternativa en la manera de concebir la epistemológica jurídica, que busca contribuir a la restauración del puente existente entre la teoría de la ciencia y la teoría del conocimiento. Restauración, porque el concepto de epistemología empleado a partir del siglo XIX ha referido, predominantemente, hacia sólo las teorías de las ciencias particulares. Ese fenómeno ha tenido importantes consecuencias para ciencias como el Derecho, que pueden evidenciarse palmariamente en muchas de las modernas teorías del derecho. Uno de esos efectos -quizá el más importante-, ha sido la de crear una brecha entre el derecho y la justicia, o en la no correcta intelección de sus relaciones.

\footnotetext{
"José Alejandro Machado Jiménez alemach94@gmail.com. Edgar Antonio Guarín Ramírez edguarin@hotmail.com. Profesores Teoría del Derecho, Universidad Católica de Colombia.
} 


\section{ABSTRACT}

This article presents an alternative in the way of conceiving the epistemological legal, which seeks to contribute to the restoration of the existing bridge between scientific theory and the theory of knowledge. Restoration, because the concept of epistemology used since the 19th century mentioned, predominantly a theory of particular Sciences, generating a substitution of the general theory of knowledge by the general theory of science. This phenomenon had significant consequences for science as law, which can become spectacularly evident in many of modern theories of law. One of these effects - perhaps the most important-, has been the create a gap between law and justice, or in the not correct intellection of its relations.

\section{Palabras Clave:}

Epistemología, gnoseología, Derecho, justicia.

\section{Key Words:}

Epistemology, gnoseology, law, justice.

\section{La cuestión}

Como todas las profesiones, la del abogado reclama acceder a un conocimiento suficiente que permita poner en práctica un saber, cuya naturaleza, libere su quehacer profesional de todo posible condicionamiento ${ }^{1}$. Asimismo, el saber de

\footnotetext{
1 La libertad de ejercicio profesional además de ser un derecho reconocido por múltiples declaraciones de derechos en ámbito internacional y de las Constituciones Políticas de diversas naciones, es manifestación de la dignidad humana frente al trabajo. Dicha libertad no tiene cabal realización si quien la ejerce no apropia para sí un saber que le permita intervenir en la realidad de manera específica e identificando pública y personalmente a quien obra con un oficio o profesión. En ese sentido la apropiación de un saber-hacer hace parte la identidad y del dominio de sí mismo; y el dominio de sí es la principal nota de toda forma de obrar
} 
cada oficio reclama el cumplimiento eficaz del fin específico que la respectiva profesión tiene ${ }^{2}$. Bajo estas premisas, la legislación colombiana regula la profesión de los abogados; lo hace mediante el Decreto 196 de $1971^{3}$ y la ley 1123 de $2007^{4}$. En dichas normas, se consagra que la principal misión del abogado es defender en justicia los derechos de la sociedad y de los particulares ${ }^{5}$.

Este marco regulativo conduce al planteamiento de una cuestión fundamental para el jurista: si la principal misión del profesional del derecho es defender los derechos de las personas en justicia, lo cual significa que su saber se especifica por la justicia, ¿cómo contribuir, desde la epistemología jurídica, a la restauración del puente que une a la teoría de la ciencia con la teoría general del conocimiento y, de esta manera, volver a recuperar la inescindible relación entre el Derecho y la Justicia?

La cuestión que se plantea no se puede dar por superada, aunque algunos pretendan hacerlo ver de esta manera. La justicia es un tema recurrente en la literatura jurídica actual. Se refiere a ella como un principio necesario para el orden social; como un concepto sistémico; un valor loable para la sociedad; como un

\footnotetext{
libre. Por tanto, por el camino del saber que se haya apropiado y sea perfeccionador verdaderamente de la realidad, es que el ser humano tiene completamente la libertad de ejercicio. (Aristóteles, 2003, 2005). Sobre el particular los estudios que actualmente existen de la antropología del trabajo evidencian la cuestión descrita, para lo cual puede consultarse a Yepes (1996, p. 121-123; 125 -132; 171-173.)

${ }^{2}$ Toda profesión tiene una finalidad específica que la diferencia de otras. Dicha especificidad le viene dada cabalmente por el objeto formal de la ciencia que se profesa y hacia la cual dirige su saber para poder cultivar efectivamente un oficio y así se pueda decir que el ejercicio es también ciencia. En el campo de algunos estudios de epistemología jurídica hay teorías que separan radicalmente el saber sobre el ejercicio del derecho, y el de la ciencia del derecho, sin unir teleológicamente lo que la conducta humana tiene en sus operables, como por ejemplo se puede observar en la teoría Egológica del derecho. (López, Gastón y otros, 2005, p. 608.)

${ }^{3}$ Aprobada el 12 de febrero, en Diario Oficial, núm. 33.255, de 1 de marzo de 1971, Bogotá.

${ }^{4}$ Aprobada el 22 de enero, en Diario Oficial, núm. 46.519, de 22 de enero de 2007, Bogotá.

5 El artículo segundo del Decreto 196 establece que La principal misión del abogado es defender en justicia los derechos de la sociedad y de los particulares. También es misión suya asesorar, patrocinar y asistir a las personas en la ordenación y desenvolvimiento de sus relaciones jurídicas. Por su parte, la ley 1123 de 2007, aunque plantea una nueva formulación en cuanto a la tipificación de las faltas disciplinarias y en cuanto al catálogo deontológico que traía el Decreto 196 de 1971, no deroga totalmente dicho decreto y, como nueva ley, mantiene vigente los artículos 1 al 3, que contienen la misma conceptualización normativa, por ello resultan compatibles con la precitada ley.
} 
ideal teórico ${ }^{6}$, etc. Empero, paradójicamente, se le estudia marginalmente, sin llegar a profundizar sobre los alcances que tiene como necesidad humana. Una muestra de ello se encuentra en el reciente proyecto de reforma constitucional a la administración de justicia en Colombia. El proyecto comienza a discurrir sobre el derecho a acceder a la justicia, pero tomándola como un concepto por amplio, general, relativo y hasta confuso. La razón por la cual toma tal presupuesto, está expresada en el mismo proyecto que acoge la tesis del Profesor Jiménez Leube para quien hablar de justicia hace necesario acudir a la filosofía; y esta disciplina la filosofía-, según la misma tesis, aleja al profesional del derecho del camino de la razón práctica. Por tanto, para plantear una reforma a la justicia sería necesario que el estudio del proyecto se concentre en la organización del Estado, en razón de que es allí en donde realmente se dirimen los conflictos que se "presentan en su seno con relación a la titularidad y efectividad de los derechos"”.

Así pues, los fundamentos teóricos que se avizoran en el trasfondo del proyecto -aunque escasos en mención-, sí llegan a ser lo suficientemente ilustrativos de lo que se está afirmando. En esa misma línea de conceptualización de la justicia, se cita la obra de Ch. Perelman (1984) en la que dice que "entre todas las nociones prestigiadas, la justicia parece una de las más eminentes e irremediablemente confusas (...). Desde hace miles de años todos los antagonistas en los conflictos públicos y privados, en las guerras, las revoluciones, los procesos, las querellas de intereses, declaran siempre y se esfuerzan por probar que la justicia está de su parte, que se invoca a la justicia siempre que se invoca a un árbitro, inmediatamente se da uno cuenta de la multiplicidad inverosímil de los sentidos que se dan a esta noción y de la confusión provocada por su uso".

\footnotetext{
${ }^{6}$ Esta tendencia a ver la justicia como un estandarte de contenido meramente teórico, intelectualista o ideológico, se ve reflejada en obras de conocidos estudiosos colombianos como el Doctor Óscar Mejía Quintana (2006). También en posiciones teóricas de autores de otras naciones como Rafael Enrique Aguilera Portales(2007).

${ }^{7}$ Congreso de la República de Colombia, Gaceta del Congreso, Año XX No. 747. ISSN 0123-9066. p. 6-7. Martes 4 de octubre de 2011. Proyectos de actos legislativos No 07 de 2011 Senado, y acumulado con los proyectos de actos legislativos No. 09 de 2011 Senado, No. 11 de 2011 Senado, No. 12 de 2011 Senado, No. 13 Senado.
} 
Un examen epistemológico más completo de la literatura sucintamente reseñada, merecería posteriores análisis; sin embargo, más que marcar unas tendencias, parecería que cualquier estudio tendría que comenzar por evidenciar la necesidad de examinar cuáles han sido los baremos sobre los que proyectan las distintas teorías. Para contribuir a tal fin, y para hacer posible una reflexión que incentive investigaciones posteriores, se han seleccionado los estudios filosóficos que algunos autores han presentado sobre la cuestión propuesta, tanto en el ámbito enciclopédico como en el del avance investigativo. Sus ideas se constituyen en un punto de partida importante para comenzar a plantear soluciones a la cuestión presentada, echando mano de otros soportes epistemológicos.

\section{Un acercamiento al estado de la cuestión y una hipótesis de solución}

El concepto de epistemología empleado a partir del siglo XIX ha referido, predominantemente, a una teoría de las ciencias particulares. Desde entonces, la teoría de la ciencia sustituyó a la teoría general del conocimiento. Ese fenómeno, surgido por cuenta de un modo de hacer filosofía, que pone al sujeto como fundamento de lo real, ha tenido importantes consecuencias para las ciencias humanas y sociales; resultados que pueden evidenciarse palmariamente en cada una de las modernas teorías del derecho. Uno de esos efectos -quizá el más importante-, ha sido el de crear una brecha entre el derecho y la justicia; brecha que, no obstante los esfuerzos de los llamados "teóricos de la tercera vía", aún sigue abierta, porque no se abandona el modo de filosofar que generó la ruptura, con sus respectivos fundamentos epistemológicos.

En efecto, la reflexión sobre la relación sujeto-objeto -cuestión fundamental en cualquier teoría del conocimiento-, se ha venido orientado predominantemente, desde los orígenes de la modernidad, hacia la puesta del sujeto como condición de la realidad ${ }^{8}$. De esta última concepción, da cuenta el argumento de Galileo, según el cual, "luz y colores (blanco o rojo), sonidos, sabores y olores no son más

\footnotetext{
${ }^{8}$ La tendencia mayoritaria de la epistemología jurídica contemporánea, heredera de la tradición cartesiana y kantiana, ha sido la de poner el conocer del hombre como condición de lo real.
} 
que nombres que no existirían sin un sujeto que siente, como tampoco cosquillas o dolores tienen una existencia objetiva en las cosas fuera de nosotros" (citado en Saumells, 1989, p. 702). Para esta manera de entender la realidad, elaborada de manera magistral y sistemática por la crítica kantiana, "las ideas no son ya conceptos abstraídos de las cosas, incapaces de agotar aisladamente la realidad de donde han sido tomados, sino más bien modelos a los que debe ajustarse la realidad, o, mejor aún, la realidad misma" (Gilson, 1974, p.49).

Esta tendencia epistemológica puede ser valorada por las consecuencias históricas a donde ha conducido. El camino de la crítica del conocimiento emprendido por Kant a finales del siglo XVIII, lo llevó a poner en el pensamiento del sujeto por vía de los a priori, no solamente las condiciones que posibilitan el conocimiento, sino incluso, los objetos mismos de ese conocimiento (García, 2004). Ese trasegar por las sendas de la crítica, ha llevado a muchos teóricos del derecho a hacer análisis de la realidad jurídica en los que se menciona y coloca a la epistemología -limitada, muchas veces, a la teoría de la ciencia, según los términos referidos ut supra- como condición de la ontología ${ }^{9}$. Consecuencia de ese particular análisis, son los diversos reduccionismos del derecho, que han sido puestos de presente por varios autores ${ }^{10}$, entre ellos, se destaca el trabajo del profesor Gabriel Mora Restrepo (2005), quien plantea cuatro reduccionismos del derecho: la negación de la metafísica, la dogmática, la hermenéutica y la técnica jurídica" ${ }^{11}$. Si se habla de "reduccionismos", es porque se ha perdido la visión de totalidad en el conocimiento de la respectiva realidad; en el campo jurídico, ese

\footnotetext{
${ }^{9}$ Es preciso aclarar en este punto, que aquí se emplea el término "ontología" de diversa manera a lo entendido por Kant, para quien: "la ontología es aquella ciencia (como parte de la metafísica) que forma un sistema de todos los conceptos y principios del entendimiento, pero sólo en cuanto se refieren a los objetos dados a los sentidos y que, por tanto, sólo a través de la experiencia pueden ser alcanzados. No alcanza lo suprasensible, que es, sin embargo, el fin final de la metafísica; pertenece, pues, a ésta sólo como propedéutica, como vestíbulo o atrio de la metafísica estrictamente dicha, y se la llama filosofía trascendental porque contiene a priori las condiciones y primeros elementos de todo nuestro conocimiento" (Citado y traducido por García, 1994, p. 31-32).

${ }^{10}$ Por ejemplo Martell (2009), Tantalean (2009), Ibarzábal (2007), Praus (2004).

${ }^{11} \mathrm{El}$ autor aclara que estos reduccionismos, en cuanto la función del jurista, le llevan, no en pocas ocasiones, a ser un simple interlocutor de viva voz de lo que la ley expresa o de lo que los jueces interpretan, con las implicaciones que ello tiene para la efectiva garantía de los derechos de las personas.
} 
fenómeno aparece de manera marcada, desde que tuvo lugar el nacimiento de la llamada "teoría del derecho"12.

Nadie niega la importancia que tiene el hecho de que, frente a la realidad jurídica, exista abundante reflexión que pueda contribuir a su cabal entendimiento; sin embargo, si esa reflexión no tiene vocación de totalidad y profundidad, se corre el grave peligro de llegar a un grado tal de exacerbación de la especulación, que se sacrifique la entidad propia de la realidad estudiada -en este caso, la del derecho-, conduciendo, en no pocas ocasiones, a una instrumentalización del mismo. El resultado de ello ya se vive al interior de la sociedad: un derecho puesto al servicio de intereses particulares en los ámbitos social, político o económico. Allí, no hay cabida para la justicia, y si se le considera, se le ve como algo ajeno al derecho o, a lo sumo, como algo "eidético" que, en las más de las veces, se torna en mera proyección de impacto simbólico a favor de ocultos intereses ${ }^{13}$.

Los acontecimientos posteriores a la II Guerra Mundial plantearon la necesidad de profundizar sobre la relación entre el derecho y la justicia. Gustav Radbruch, da cuenta de ello al afirmar -refiriendo a la Alemania de Hittler-, que allí hubo pronunciamientos judiciales inhumanos, basados en leyes que, junto con ellos, carecían de validez jurídica, porque un juez no puede aplicar una ley injusta y criminal. Esa denuncia del filósofo del derecho alemán, se plasma de manera inequívoca en lo que se conoce como la "fórmula de Radbruch", según la cual, donde haya conflicto entre seguridad jurídica y justicia, éste debe resolverse a favor de la seguridad jurídica, a no ser que la contienda entre ley y justicia alcance

\footnotetext{
${ }^{12}$ Según los profesores Cárdenas y Guarín (2006), "parece que el significante "teoría del derecho” es preciso atribuirlo a Rudolf Stammler, en sus discusiones con la escuela histórica hacia 1888. Aspiraba a una teorización general del derecho positivo, superadora de las conceptualizaciones fragmentarias de los empíricos del derecho". (p. 108).

13 Por ejemplo, apelando a constructos jurídicos, las decisiones de los jueces en materias constitucionales, parecen que por su impacto populista resultan vinculadas a fenómenos ideológicos, y no a una profundización de lo jurídico, como lo ha podido evidenciar recientemente Landau (2011, p 53-56). Desde la perspectiva socio-jurídica y respecto el impacto de contenido simbólico de las normas, el estudio presentado por el Prof. Botero (2003) muestra también cómo la instrumentalización del derecho positivo para los intereses particulares y juegos de poder aparece asociado a los fenómenos de injusticia y corrupción generalizada.
} 
una medida tan insoportable que la ley sea arbitrariedad: allí primará la justicia (Radbruch, 1980). Radbruch es el reflejo de una constante, presente de manera acentuada desde mediados del siglo pasado, que muestra cómo la mayoría de los estudios que se adelantan sobre el derecho y su validez, tienen contenido filosófico $^{14}$.

Así las cosas, desde hace cerca de sesenta años, en los diferentes acercamientos hechos a las cuestiones jurídicas, se percibe un retorno hacia la filosofía del derecho. Sin duda, los esfuerzos realizados en este sentido por autores como Arthur Kaufmann -discípulo de Gustav Radbruch-, Ronald Dworkin y Robert Alexy, entre otros, que hacen parte de los llamados "teóricos de la tercera vía", han sido y siguen siendo especialmente relevantes y contribuyen a enriquecer la reflexión. Ellos, se han esforzado por inquirir los fundamentos del conocimiento jurídico, más allá de lo meramente fenoménico, y, por eso, en un gran esfuerzo por determinar con precisión el objeto y el método de la ciencia del derecho, han vuelto a poner en consideración conceptos jurídicos fundamentales como el de la persona, el respeto por su dignidad, la equidad y la justicia, entre otros. Ahora bien, estas tendencias epistemológicas que, de una u otra forma, dan muestra de que se está volviendo a tender el puente entre el conocimiento y la realidad, presentan el inconveniente de seguir estando emparentadas con el método propio que inspiró a la crítica del conocimiento y que pone al sujeto (individual o colectivo) como fundamento de lo real.

Urge entonces, a manera de hipótesis de solución a la problemática planteada, volver a tender el puente entre la teoría de la ciencia y la teoría general del conocimiento, o lo que es lo mismo, entre la epistemología y la gnoseología. Desde esta perspectiva, el conocimiento de la realidad -de cualquier realidad-, exige indagar, no sólo por el contenido del conocimiento a partir de los fenómenos, y por los métodos empleados para adquirirlo, sino también por cuestiones de particular importancia tales como el concepto de conocimiento que

\footnotetext{
14 Puede consultarse D'agostino (2007) y desde otra frontera filosófica, un ejemplo que evidencia la afirmación se encuentra en las obras Theodor (1962).
} 
subyace al abordaje de estos interrogantes, el objeto del mismo, los aspectos que de él se pretenden analizar, así como los términos en que se establece la necesaria relación existente entre el sujeto que conoce y el objeto conocido. Sobre esta última cuestión, vale la pena recordar que, es lugar común, el aceptar que el progreso de la epistemología está anclado a la penetración de la realidad(Saumells, 1989) y que, de la manera como se entiende la relación sujeto y objeto, dependen -en buena parte-, los demás interrogantes en torno al conocimiento humano ${ }^{15}$.

\section{Algunas cuestiones metodológicas}

Metodológicamente el problema ha de ser abordado siguiendo los caminos propios de la filosofía, dada la naturaleza misma del objeto de estudio. Lo anterior, en razón de que el conocimiento filosófico responde a interrogantes tales como el qué, el por qué, el para qué se conoce, mirando los fundamentos, lo cual no es propio de la ciencia, que pone especial énfasis en el fenómeno, en sus causas próximas y en la manera de conocerle. Los filósofos de la antigüedad son un buen ejemplo de la manera como procede la filosofía y, por eso, al emplear el término episteme lo refirieron no a los saberes particulares de cada una de las áreas del conocimiento, sino como un saber general, siempre referido a lo real. De allí que la filosofía, en cuanto ciencia de ciencias, se consideraba la forma de conocimiento llamada a ocuparse de esa episteme, con una intencionalidad especial: la que respecta a los fundamentos y principios de la realidad (Aristóteles, 1997). Esa manera de concebir el conocimiento, que no creaba ruptura entre lo particular y lo general, sino que ponía acento en la distinción y complementación entre una y otra, permeó buena parte de la historia.

\footnotetext{
${ }^{15}$ Lo anterior muestra que la tarea del epistemólogo del derecho es compleja, toda vez que le compete inquirir por aquello que específica el saber jurídico. Eso, está más allá de lo meramente óntico, esto es, de lo simplemente dado. La cuestión lo lanza, indefectiblemente, hacia lo onto-lógico, es decir, hacia los principios y fundamentos. El mismo origen de la palabra epistemología (ep-istaistai), da cuenta de la amplitud de esa tarea del epistemólogo: el término refiere al saber; a un "estar cerca" para saber" y, quien sabe, es capaz de dar cuenta de lo que son las cosas y no sólo de cómo se presentan.
} 
El método filosófico plantea la necesidad de realizar un análisis a la realidad que se impone con sus evidencias; el jurista que trasiega por esos senderos, se encuentra con que el ser personal, por su misma estructura ontológica, es suppositum, es decir, lo que nosotros llamamos "sujeto". Cárdenas y Guarín (2006), refieren que el término suppositum significa sostén o soporte y, en el caso de los individuos humanos ese "supósito" es sustancialmente distinto del de los individuos de otras especies de animales, y, por eso, porque su sostén se especifica por su inteligencia y su voluntad, reciben el nombre de personas. En el ser personas, se encuentra el fundamento mediante el cual le es posible la relación del hombre con las cosas y la apropiación de las mismas; relación que es real y no mera ficción. Esas cosas que el sujeto llama suyas, constituyen el universo de sus derechos, cuyo arrebatamiento configura una verdadera injusticia.

\section{Los resultados: la propuesta de un camino epistemológico para restablecer} la inescindible relación entre la teoría de la ciencia y la teoría general del conocimiento

Siguiendo la senda metodológica propuesta, es posible volver a tender el puente entre la epistemología y la gnoseología y, por esa vía, entre el Derecho y la justicia, atendiendo a sus reales relaciones. En los últimos años se ha venido haciendo especial énfasis en el hecho de que la epistemología, en cuanto refiere al conocimiento, es inseparable de la filosofía (Caballero, 1989) y, por eso, se hacen esfuerzos académicos -especialmente por parte de aquellos que buscan valorar adecuadamente los problemas que surgen en torno al conocimiento-, por volver a tender el referido puente entre teoría de la ciencia y teoría general del conocimiento. Ese esfuerzo implica una forma de indagación sobre lo real que, como se refería en el acápite metodológico, se ocupe de cuestiones de particular importancia como el concepto de conocimiento que subyace al abordaje de los temas jurídicos, el objeto del mismo, los aspectos que de él se pretenden analizar, así como los términos en que se establece la necesaria relación existente entre el sujeto que conoce y el objeto conocido. 


\subsection{Una epistemología jurídica que vaya más allá de modelos causales}

\section{y atienda a las propiedades de la razón humana}

No hay duda de que los teóricos del derecho que han trasegado por estas sendas de la crítica trascedental kantiana -en sus múltiples manifestaciones-, han dado lugar a escritos que son verdaderas piezas de coherencia formal; quizá sea esa la razón por la cual resulta tan difícil desprenderse de ella. Incluso, cuando se hacen propuestas que toman distancia respecto de esa postura teórica, se consideran carentes de valor. Sin embargo, si se identifican con detalle la manera como procede la razón humana, es posible percatarse de que ese no es el único camino para alcanzar aquel fin que la misma legislación le ha dado al jurista y que es referido al iniciar estas líneas: defender, en justicia, los derechos de las personas. No sobra recordar en este punto que, desde los orígenes mismos del pensamiento jurídico, la pregunta sobre la justicia y su lugar en el estudio del derecho, estuvo presente; empero, el camino seguido para resolverla, fue distinto: se tomó la realidad como condición previa del conocimiento. Lamentablemente esta vía no ha podido ser suficientemente valorada y conocida por las modernas teorías jurídicas, por lo menos en aquellas que han ejercido mayor influencia en Colombia.

Tomando las propiedades de la razón humana es posible aclarar, entonces, los alcances de cada uno de los dos emparentamientos filosóficos que se han mencionado, a saber, el que da primacía a la realidad y el que da primacía al sujeto en el acto de conocer. La primera propiedad es que la razón humana no puede actuar sin algo que ya está conociendo, es decir, que en cuanto los hombres piensan, ya poseen lo que piensan; esta propiedad es un hábito que hace posible captar la verdad de los primeros principios, que son los que permiten a cada sujeto conocer la verdad sin ninguna duda o vacilación. Si esto no fuera así todo el conocimiento sería hipotético, no se podrían tomar decisiones, sólo existirían opiniones y, por lo tanto, no tendría sentido preguntarse por el por qué, el para qué, el cómo se conoce o el cómo presenciar elementos básicos que permitan la comunicación humana. Los primeros principios, son llamados así, 
porque no necesitan demostración, ya que son los primeros juicios de la inteligencia. El primer principio es el de contradicción, enunciado así por Aristóteles (1997): "Y, puesto que es imposible que la contradicción de una misma cosa sea simultáneamente verdadera, es claro que tampoco cabe que los contrarios se den simultáneamente en la misma cosa; pues uno de los dos contrarios es privación no menos que contrario, y privación de substancia; y la privación es negación de algo en cierto género determinado. Por consiguiente, si es imposible afirmar y negar al mismo tiempo con verdad, también será imposible que los contrarios se den simultáneamente, $y$, o bien ambos se darán en algún aspecto, o uno en algún aspecto, y el otro, absolutamente" (p. 55).

Por el principio de contradicción es que hay entes reales, y porque los hay es que es posible el conocimiento, de modo que si se afirma y se niega simultáneamente el ente conocido, no es posible el conocimiento porque se incurre en una contradicción. Quienes han pretendido negar la posibilidad de existencia de este principio, muestran que dicha negación acaba siendo incongruente, puesto que en lo que terminan, es en la afirmación de la existencia del mismo. En esta situación se pueden encontrar las teorías jurídicas cuando respecto del principio de contradicción se postulan los planteamientos escépticos que niegan la posibilidad de aplicación de dicho principio por cuanto entienden al derecho como una realidad de imposible fundamentación o justificación (Kennedy, 1999). Son planteamientos que incluyen, como presupuesto, que respecto del derecho no es posible distinguir lo verdadero de lo falso, lo bueno de lo malo. No hay lógica de orden especulativo que pueda valer; sí, en cambio, explicaciones monistas o nihilistas. Así por ejemplo lo que explicaría la existencia de alguna exigencia jurídica serían las efervescencias ideológicas o axiológicas de grupos de poder, los resultados de la confrontación de intereses particulares, los tipos ideales de contenido "débil" como el del "juego democrático", e incluso de manera ecléctica la concurrencia de todas las anteriores; y ello, no porque sean tomados como fundamento -como respuestas que aproximen a un qué, para qué y cómo se conoce lo jurídico- sino como formas de explicar, de construir paradigmas de 
validez juntando las percepciones de quienes vayan posicionándose a través un discurso de contenido plausible. Estas posturas olvidan que cualquier forma de explicación, es ya una ruptura del principio escéptico del cual parten. Sobre el particular, conviene recordar las palabras de Tomás de Aquino (1954): Que existe la verdad, es evidente por sí mismo, puesto que quien niega que la verdad existe está diciendo que la verdad existe; pues si la verdad no existe, es verdadero que la verdad no existe. Pero para que algo sea verdadero, es necesario que exista la verdad (p. 108).

Una segunda propiedad de la razón humana se encuentra en su posibilidad de discurrir mediante la realización de pasos intermedios entre premisas y conclusiones para llegar a una verdad. Se parte de una verdad y se llega a otra. La posibilidad de discurrir hacia un nuevo conocimiento impide que se le pueda atribuir el carácter de racional a los llamados discursos circulares y a las conclusiones que vayan más allá de lo afirmado en las premisas. El conocimiento en su discurrir tiene un orden al que se le llama lógica; si ese orden no se respeta, el discurso no es racional. Y, respecto de este principio, su negación opera en las distintas formas como se hacen y presentan los argumentos, cuando ellos concluye en paralogismos o falacias.

En las teorías jurídicas pueden encontrarse planteamientos previos o supuestos que actuando como premisas no consigan deducir conclusiones de contenido cierto o absoluto. Y la razón de orden lógico es que "la conclusión de un razonamiento válido no va más allá ni afirma más de lo que está contenido en las premisas. Si la conclusión, ilegítimamente va más allá de lo afirmado en las premisas, el razonamiento no es válido" (Copi, 1981, p. 227). Si la episteme de la que parte la respectiva teoría jurídica está sustentada sólo en hechos de naturaleza contingente, ideologías o regímenes políticos, las conclusiones que presente la teoría jurídica no pueden ser sino sucedáneos de carácter contingente, ideológico o de un determinado régimen político. No se podría entonces presenciar respecto del derecho notas de contenido aglutinante o radicales, sino sólo aquellas que puedan ser relativas a los fenómenos de los cuales resultan, 
como por ejemplo, estados de conciencia, opciones democráticas, fuerzas productivas en los económico o fuerzas políticas. No existirían derechos sino sólo pretensiones, intereses y presiones de parte.

Siempre que se ponga de presente -y en su justo lugar-, el problema real del conocimiento humano, se ha de advertir que el intelecto humano no se satisface con respuestas dadas a partir de uno o varios modelos casuales porque, por su propia naturaleza, busca ir más allá de las meras apariencias; son inquietudes que terminaron convirtiéndose en exigencias del vivir humano civilizado a partir de las cuales el pensamiento de la filosofía clásica marca un único hito (Jaeger, 2001). La pretermisión de estas exigencias respecto del conocimiento de lo jurídico, termina por cobrar un precio alto a la necesidad de rigor que demanda el estudio de los problemas de justicia o eficacia del derecho. La ausencia o presencia de dicho rigor, se manifiesta después en las posibles soluciones en el campo legislativo o en el del raciocinio judicial. Es del respeto por las propiedades de la razón de las que emana el rigor, y no sólo de la mera coherencia formal de un discurso.

Al pretender conocer la realidad jurídica, solamente a partir de modelos meramente casuales, se desprecia un factor que la compone, cual es, el fundamento en la que se causa. No puede obviarse tal elemento de prexistencia, pues ello conlleva a una simplificación que excluye la posibilidad que, respecto del conocimiento, se pueda ir más allá de un fenómeno o experiencia. Si en los modelos casuales se contienen ideas generales formadas a partir de notas características y comunes a diversos fenómenos -siendo extensibles a otros casos- y se presenta a la experiencia como la única voz autorizada para saber si se extiende a muchos o a pocos casos, la pretensión de validez universal de tales modelos no podría confirmarse nunca de modo definitivo. Aceptar que sólo a partir de la experiencia ocasional se genera una teoría para luego terminar respondiendo a una particularidad (como son las del mundo del derecho), es restringir la reflexión racional que posibilita el entendimiento humano, que tiene 
vocación de trascendencia y que, en cuanto tal, busca la verdad, también en el obrar humano.

Pero a pesar de las limitaciones que con respecto al conocimiento de la realidad puedan estar presentes en las modernas iusteorías, tributarias de la filosofía del sujeto, no por ello se puede llegar a concluir que muchos de sus postulados pudieran llegar ser desechados a razón del mero punto de partida; al contrario, si se quiere hacer una epistemología del derecho que contribuya a superar los agudos problemas de justicia que se presentan en la actualidad, el examen de aquellos postulados permitirá buscar su grado de verdad; verdad que no puede reducirse o conformarse con la coherencia lógico-formal, sino que tiene que dar cuenta de lo real. Como lo afirma Etienne Gilson (1974): "lo que hace falta es que la epistemología, en vez de ser una condición de la ontología, se desenvuelva en ella y con ella, siendo al mismo tiempo explicadora y explicada, sosteniéndola y siendo sostenida por ella, como se sostienen mutuamente las partes de una filosofía verdadera". (p. 84).

\subsection{Una epistemología que indague con profundidad por los objetos material y formal de la Ciencia Jurídica}

El camino señalado por Etienne Gilson en la cita con la que se terminó el apartado anterior, es el que han trasegado los llamados "realistas jurídicos clásicos" (Hervada, 1988). Haciendo uso del método realista-razón por la cual se llaman "realistas"-, parten de la base de que, es el objeto de estudio de la ciencia el que determina el método a seguir para su abordaje, y no al revés ${ }^{16}$. Por ende, su principal tarea ha sido la de abordar el análisis del orden de lo real que se proponen estudiar y forjar el instrumento adecuado a ese orden, para penetrarlo. En ese sentido, el realismo jurídico clásico hace un importante aporte a la ciencia del derecho a partir de una sólida y estructurada teoría general del conocimiento jurídico, en la medida en que hace tomar conciencia de que el objeto de la

\footnotetext{
${ }^{16}$ De esta manera, escapa del exceso en el que incurriera Descartes hace cerca de cuatrocientos años, cuando decretó a priori, que el método de una ciencia como las matemáticas, servía para la totalidad de lo real: así como las matemáticas tienen su objeto y su método (el objeto de la matemática es la cantidad y su método eminentemente deductivo), la ciencia del derecho tiene su objeto y su método.
} 
epistemología no es el pensamiento, sino el conocimiento, esto es, la captación de un objeto de estudio -el del derecho-, por parte del pensamiento; y una captación que, si bien parte de lo fenoménico, va más allá de ello ${ }^{17}$.

El primer paso en este camino epistemológico, será el de determinar el objeto material sobre el que recae la ciencia jurídica. El objeto material corresponde a la realidad (materia) de la que se ocupa determinada ciencia. Para el caso de la ciencia del derecho, podría afirmarse -como de hecho ha sucedidoque su objeto material son las normas, o los hechos sociales, o las decisiones de los jueces. Sin embargo, si se hace un análisis más hondo, es posible percatarse de que, tanto las normas, como los hechos sociales y la jurisprudencia, tienen como común denominador que refieren a una misma realidad: el comportamiento humano. El darse cuenta de ello, conduce a ubicar la ciencia jurídica como parte del conjunto de ciencias prácticas; en tal sentido sostiene Martínez (1963):

El conocimiento jurídico no es en modo alguno un saber especulativo. Es más bien, con todas las consecuencias que ello lleva consigo, un saber práctico. El objeto del conocimiento jurídico no es una esencia puramente especulable, puesta ante nuestra consideración para ser contemplada. Se trata aquí de conductas, acciones, decisiones humanas, es decir objetos que hacen referencia a la realidad concreta, y que no pueden ser entendidos -en tanto que jurídicosprivados de esa referencia a la realidad (p. 16-17).

Cuando los legisladores, producto de su captación de la realidad social, establecen las normas, lo que buscan es ordenar la conducta humana; lo mismo sucede con los jueces y sus decisiones: juzgan la conducta humana; y los hechos sociales, también son el producto de la conducta humana. Así pues, más allá de los hechos, de las normas o de las decisiones de los jueces, el jurista se ocupa de la conducta del hombre.

\footnotetext{
${ }^{17}$ Con ello, no se trata de huir a la crítica del conocimiento; se trata, más bien, de ser críticos frente a las teorías del derecho cuyos pensamientos no son siempre conocimientos, dado que no hay forma de contrastarlos con un objeto que existe con independencia suya, puesto que: res sunt, ergo cogito, et non: cogito ergo sum.
} 
Ahora bien, como es posible que dos ciencias recaigan sobre el mismo tema u objeto de estudio, hay que buscar el objectum formale, o aquel aspecto que, dentro del mismo objeto material, es del interés de los investigadores dentro de las diversas ciencias. Dicho objeto, que especifica a la ciencia, despierta los diferentes intereses que tiene el sujeto cognoscente frente a una realidad que es cognoscible, inteligible y que determina siempre la manera de abstraer y definir ${ }^{18}$. En esta línea, Tomás De Aquino, invita a tener en cuenta las diferencias que, a nivel de conocimiento, surgen por cuenta de la diversificación de los objetos: "las formas recibidas en la materia procedentes del mismo agente no son de la misma especie" (p. 60). Por eso, la indagación sobre la realidad jurídica, en orden a su conceptualización y delimitación, puede hacerse de diversas formas, atendiendo al estudio de los distintos aspectos que encierra ese objeto de conocimiento. Es eso lo que posibilita el que, respecto del derecho, se pueda hablar de dogmática jurídica, teoría del derecho, sociología jurídica, antropología jurídica, filosofía del derecho, etc. Cada uno de estos saberes tiene en común con los otros que se acercan a analizar una misma realidad y, si bien se hace con intereses distintos, a todos les preocupa lo mismo: el orden social que se garantiza por la justicia. Por eso, es la justicia la que especifica el saber del jurista.

Aún hay muchos que, aferrados al fracasado positivismo jurídico en sus diversas formas, estiman que este camino epistemológico, que pone al ser por encima del pensar y al objeto por encima del método, atenta contra la "pureza de la ciencia jurídica"; ven así las cosas, porque aún subsiste la idea de que hablar de justicia en el derecho, genera "impureza", toda vez que la justicia es un mero ideal, de contenido relativo (Kelsen, 2001). Sobre dicho particular, cabría tomar como referencia ilustrativa la imagen del Catoblepo: aquella figura de la mitología etíope

\footnotetext{
${ }^{18}$ Conviene recordar, en este punto, que una de las consecuencias de la crítica kantiana es el haber llevado a pensar que lo práctico no es científico. Ello porque, desde Kant, la ciencia se agota en lo teórico y, de ningún modo puede tener como objeto la acción; la ciencia no puede ser, dentro de este esquema, generadora de normas de conducta, de valores que exigen ser vividos. El concepto de "ciencia práctica" resulta, por ende, contradictorio en sí mismo toda vez que lo práctico es cambiante, depende del "sentimiento colectivo" de cada lugar y época. Es por eso que Kant, en su crítica de la razón práctica, termina poniendo la voluntad del sujeto como fundamento de la moral (García, 2004).
} 
correspondiente a ese animal que destruye con la mirada y que mirándose a sí mismo se autodestruye; ello, porque ni el más positivista de los positivistas, ni el más analítico de los analíticos, puede negar el hecho real de que sin justicia, no es viable ninguna sociedad y que los problemas de la justicia son la tarea del jurista puesto que es a él a quien le corresponde velar por el respeto de los derechos.

\section{A manera de corolario}

Al iniciar este escrito, se habló de la necesidad de que, para el ejercicio profesional de los abogados, se especifique un tipo de saber con rigor científico y libre de condicionamientos. Esa necesidad, impele tomar una opción por un método de acceso a lo real que permita mostrar que es posible conocer el derecho sin estar condicionado por intereses económicos, políticos, ideológicos, religiosos o moralistas ${ }^{19}$. Para mostrar cómo se llega por la vía filosófica al momento de optar y las consecuencias de cada elección, la obra del conocido profesor español Carlos Cardona (1973) -en la línea teórica explicitada en este escrito- explica cómo, en el momento en el que se toma la realidad de manera independiente al sujeto pensante, se llega al conocimiento del fin, y siendo la razón de fin la que especifica un objeto conocido, es por lo que este sistema permite de manera lógica conocer el fin específico del obrar según una particular forma de saber, y que en el caso que se ha estudiado en el presente escrito, corresponde al de la profesión del jurista.

Como se ha puesto de presente, la connotación de la epistemología reducida a la teoría de la ciencia, por sí sola, no ha logrado dar cuenta de la complejidad que comprende la realidad del derecho. De allí la propuesta hecha en

\footnotetext{
${ }^{19}$ Este interés, o si se quiere ver así preocupación, ha estado presente en la reflexión iusfilosófica proveniente de las más marcadas y diversas tendencias como por ejemplo "Al caracterizarse como una doctrina "pura" con respecto del derecho, lo hace porque quiere obtener solamente un conocimiento orientado hacia el derecho, y porque desearía excluir de ese conocimiento lo que no pertenece al objeto precisamente determinado como jurídico. Vale decir: quiere liberar a la ciencia jurídica de todos los elementos que le son extraños. Este es un principio fundamental en cuanto al método. Pareciera tratarse de algo comprensible de suyo. Sin embargo la consideración de la ciencia jurídica tradicional, tal como se ha desarrollado en el curso de los siglos XIX y XX, muestra claramente que lejos esa ciencia ha estado de satisfacer la exigencia de pureza. En manera enteramente acrítica, la jurisprudencia se ha confundido con la psicología y la sociología, con la ética y la teoría política." (Kelsen, 1982, p. 15).
} 
el sentido de volver a tender el puente entre la gnoseología y la epistemología. Conocer un área de la realidad, atendiendo a su especificidad, a su fin, es un problema gnoseológico. Sobre esa base, la epistemología, puede indicar los contenidos que de allí se desprenden y el modo de alcanzar dicho fin ${ }^{20}$. Esta significación del significante "epistemología jurídica", permite abordar el estudio de la realidad del derecho desde todos los aspectos y perspectivas, a la vez que facilita la determinación de lo que le hace específico, esto es, la realidad de la justicia. Conviene recordar aquí, las palabras del ilustre politólogo norteamericano Michael Sandel (2011): "jamás podemos prescindir de la vena enjuiciadora de la justicia. Parece que pensar en la justicia, nos arrastra sin remedio a pensar en la mejor manera de vivir" (p. 18).

\section{REFERENCIAS}

Aguilera Portales R. E. (2007) "Posibilidad, sentido y actualidad de la filosofía del derecho" en Revista lus et Praxis, año 13 No. 2, pp. 307-341.

Alexy, R. (2007). ¿Derechos humanos sin metafísica? En Doxa, Cuadernos de Filosofía del Derecho, No 30, p. 247.

Aristóteles. (2003). Ética a Nicómaco. Madrid: Editorial Gredos.

Aristóteles. (1997). La metafísica. Madrid: Editorial Gredos.

Aristóteles. (2005). La política. Madrid: Editorial Alianza.

De Aquino. T. (1954). Suma teológica. Madrid: Editorial BAC.

Ballnow. O. (2001). Introducción a la teoría del conocimiento. Buenos Aires: Editorial Amorrortu.

\footnotetext{
${ }^{20}$ Ello exige superar aquella ruptura establecida por el nominalismo, entre el acto de conocer y el del acto de pensar. El conocimiento "puro", sin fingimientos, de lo que es real por llamarlo así, se dará a partir del método de Descartes y que consiste en que para llegar al acto de conocer (así entendido como "puro") se debe "comenzar a pensar" sin presupuestos (o sea con ideas de las que no se conozca su origen o su valor). El acto de "comenzar a pensar" sin presupuestos será un acto voluntario de control y análisis propio del método que hará del conocimiento un acto que dependa de que esa facultad humana (la voluntad) se ejerza según un modo que logre pensar "sin presupuestos". Y entonces será la voluntad la que predomine afirmando o negando la realidad, pero no porque la inteligencia identifique una semejanza o desemejanza en acto sino porque es la voluntad misma la que la causa: quiere pensar y sin presupuestos. El conocimiento que sea verdadero dependerá de una particular forma de acto voluntario que, según criterio establecido previamente, produzca un estado subjetivo de certeza o satisfacción de haber logrado pensar sin presupuestos.
} 
Botero B. A. (2003). Formas contemporáneas de dominación política: el síndrome normativo y la eficacia simbólica del derecho, Jornadas de derecho natural. Recuperado el 08 de Septiembre de 2011 de: http://derechonatural.tripod.com/ponencias/botero.htm[visitado 08/09/11].

Botero B. A. (2004). Nuevos paradigmas científicos y su incidencia en la investigación jurídica, En Revista de Derecho Universidad del Norte No. 21, p. 163-199.

Bourdieu. P. (2000). La fuerza del derecho. Bogotá: Editorial Siglo del hombre. Caballero, S. (1989), Gnoseología En Enciclopedia GER, Madrid: Editorial Rialp. Cárdenas. A. y Guarín. É.. (2006). Filosofía y teoría del derecho. Bogotá: Usta. Cardona. C. (1973). Metafísica de la opción intelectual. Madrid: Editorial Rialp. Carpintero F. (2010). Métodos científicos y método del derecho: una historia superada, En Persona y Derecho, No. 62. p. 29-58.

Copi. I. (1981). Introducción a la lógica. Buenos Aires: Editorial Eudeba.

D'agostino. F. (2007). Filosofía del derecho. Bogotá: Editorial Temis.

Descartes. R. (1989). Reglas para la dirección del espíritu. Madrid: Editorial alianza.

García. M. M. (2004). La filosofía de Kant. Bogotá: Editorial Cristiandad.

García M. A. (1994). Razón y Praxis. Valparaíso: Editorial Edeval.

Gilson. E. (1974). El realismo metódico. Madrid: Editorial Rialp.

Hervada, J. (1988). Apuntes para una exposición del realismo jurídico clásico. Revista Dikaion, No. 2. p. 7-19.

Ibarzábal, Ignacio M. (2007). El maniaco del unisono. Una crítica al positivismo por su reduccionismo epistemológico. En Dikaion No. 16 pp. 91-103.

Jaeger. W. (2001). El pensamiento filosófico y el descubrimiento del cosmos. En Paideia: los ideales de la cultura griega. México: Editorial fondo de cultura económica.

Kelsen. H. (1982). Teoría pura del Derecho. México: Universidad Nacional Autónoma de México.

Kelsen. H. (2001). ¿Qué es la justicia? Barcelona: Editorial Ariel.

Kennedy. D. (1999). A Critique of adjudication. Cambridge: Harvard University Press.

Landau, D. (2011). The reality of social rights enforcement. Harvard International Law Journal, Vol. 53, p 53-56. 
López, Gastón y otros. (2005). Teoría Egológica del derecho. En Diccionario jurídico. Buenos Aires: Editorial Lexis Nexis.

Martell, Daniel A. (2009) Neuroscience and the law: Philosophical differences and Practical Constrainst, en Behavioral Sciences and the law, No 27, pp. 123-136.

Martínez D. J. (1963). La estructura del conocimiento jurídico. Pamplona: Editorial Universidad de Navarra.

Mejía Quintana. O. (2006) en "Elementos para una reconstrucción del estatuto epistemológico de la filosofía del derecho" en Humanitas (No. 33), Nuevo León: Centro de Estudios Humanísticos, Universidad Autónoma de Nuevo León. pp.

Mora. G. (2005). Ciencia jurídica y arte del derecho. Chía: Ediciones Jurídicas Gustavo Ibáñez. y Universidad de la Sabana.

Praus, Gerold, (2004) El problema de la deducción de una obligación. El deber para la teoría y para la práctica, en Anuario Filosófico, XXXVII, pp. 631-644.

Radbruch. G. (1980) Arbitrariedad legal y derecho supralegal. En El hombre en el derecho. Buenos Aires: Editorial Depalma.

Rawls. J. (1995). Teoría de la justicia. Barcelona. Editorial Fce.

Ricoeur. P. (2008). Lo justo. Santiago de Chile: Editorial Jurídica de Chile.

Sandel. M. (2011). Justicia ¿hacemos lo que debemos? Barcelona: Debate editorial.

Santos. B. (1987). Discurso sobre las ciencias. Sao Paulo: Editorial Afrontamento.

Saumells, R. (1989). Epistemología. En Enciclopedia GER. Madrid: Editorial Rialp.

Tantalean Odar, Reynaldo Mario, (2009), La adimensionalidad de la tridimensionalidad jurídica: un fantasma llamado derecho, en Derecho y cambio social, No. 16, año VI, , en WWW.derechoycambiosocial.com.

Theodor W. A. (1986). Dialéctica Negativa. Madrid: Taurus Ediciones.

Theodor W. A. (1962). El ensayo como forma. En Notas de Literatura. Barcelona:

Ediciones Ariel.

Yepes S. R. (1996). Fundamentos de antropología. Barañáin: Editorial Eunsa.

Zambrano, P. (2007). Objetividad en la interpretación judicial, objetividad en la moral.

Revista Persona y Derecho No. 56, p. 281-326. 